\title{
Avenues of research in dietary interventions to target tumor metabolism in osteosarcoma
}

\author{
Taiana Campos Leite ${ }^{1,2}$, Rebecca Jean Watters ${ }^{3,4,5}$, Kurt Richard Weiss ${ }^{3,5}$ and Giuseppe Intini $1,2,5,6,7,8^{*}$ (1)
}

\begin{abstract}
Osteosarcoma (OS) is the most frequent primary bone cancer, affecting mostly children and adolescents. Although much progress has been made throughout the years towards treating primary OS, the 5-year survival rate for metastatic OS has remained at only $20 \%$ for the last 30 years. Therefore, more efficient treatments are needed. Recent studies have shown that tumor metabolism displays a unique behavior, and plays important roles in tumor growth and metastasis, making it an attractive potential target for novel therapies. While normal cells typically fuel the oxidative phosphorylation (OXPHOS) pathway with the products of glycolysis, cancer cells acquire a plastic metabolism, uncoupling these two pathways. This allows them to obtain building blocks for proliferation from glycolytic intermediates and ATP from OXPHOS. One way to target the metabolism of cancer cells is through dietary interventions. However, while some diets have shown anticancer effects against certain tumor types in preclinical studies, as of yet none have been tested to treat OS. Here we review the features of tumor metabolism, in general and about OS, and propose avenues of research in dietary intervention, discussing strategies that could potentially be effective to target OS metabolism.
\end{abstract}

Keywords: Osteosarcoma, Tumor metabolism, Caloric restriction, Fasting, Ketogenic diet, Quercetin

\section{Osteosarcoma overview}

Osteosarcoma (OS) is the most frequent primary bone cancer, although it is relatively rare in the general population, with $2-3$ cases per million per year, accounting for $2 \%$ of pediatric cancers. There are two peaks of incidence-the first and highest is in children and adolescents, and the second one is in elderly ( $>65$ years) - , with a 1.4 to 1.0 male-to-female ratio, demonstrating male predominance. While the pediatric tumors are typically related to bone growth, the adult tumors are linked to Paget's disease or radiation exposure. The most common locations are long bones, but other bones may develop OS, including the jaws and pelvis [1-6]. This tumor is characterized mainly by mesenchymal cancer cells that produce immature bone or osteoid. There are

\footnotetext{
${ }^{*}$ Correspondence: gii5@pitt.edu

${ }^{6}$ Department of Periodontics and Preventive Dentistry, University of Pittsburgh School of Dental Medicine, Pittsburgh, PA, USA

Full list of author information is available at the end of the article
}

several histologic subtypes: osteoblastic, chondroblastic, fibroblastic, small cell, telangiectatic, high-grade surface, and extra-skeletal. They are further separated according to severity: high-grade (most aggressive), intermediategrade, and low-grade (least aggressive). The most common type-around $85 \%$ of cases-is termed conventional OS: a high-grade tumor that develops in the intramedullary space (mostly osteoblastic subtype); while the other $15 \%$ correspond to intermediate-grade and low-grade OS, with periosteal (mostly chondroblastic subtype, located in the periosteum) and parosteal (mostly fibroblastic subtype, located on the surface of bones, over the periosteum) presentations, respectively $[4,5,7]$. OS, therefore, displays a very heterogeneous spectrum of phenotypes, reflecting an equally heterogeneous genetic configuration. Approximately $30-40 \%$ of patients with primary OS are expected to develop local relapse or metastases, the majority of which are to the lungs, accounting for most OS deaths $[2,8]$.

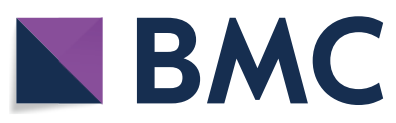

(C) The Author(s) 2021. Open Access This article is licensed under a Creative Commons Attribution 4.0 International License, which permits use, sharing, adaptation, distribution and reproduction in any medium or format, as long as you give appropriate credit to the original author(s) and the source, provide a link to the Creative Commons licence, and indicate if changes were made. The images or other third party material in this article are included in the article's Creative Commons licence, unless indicated otherwise in a credit line to the material. If material is not included in the article's Creative Commons licence and your intended use is not permitted by statutory regulation or exceeds the permitted use, you will need to obtain permission directly from the copyright holder. To view a copy of this licence, visit http://creativecommons.org/licenses/by/4.0/. The Creative Commons Public Domain Dedication waiver (http://creativeco mmons.org/publicdomain/zero/1.0/) applies to the data made available in this article, unless otherwise stated in a credit line to the data. 
The etiology for OS remains elusive, and there is no single driver gene mutation responsible for its development; instead, numerous genetic alterations have been associated with OS $[4,6,9]$. Studies have shown that OS carries several chromosomal structural alterations, leading to mutations and even deletions or amplification of genes. Variations involving TP53 and RB1 genes are regarded as the leading causes for OS. In fact, transgenic murine models with conditional $p 53$ and $R b 1$ knockouts have been shown to successfully develop spontaneous OS, modeling human osteosarcomagenesis [10, 11]. The rise of more modern and sensitive tools in molecular biology has allowed researchers to identify alterations in a plethora of genes related to different pathways in OS. Along with TP53 and RB1, other commonly affected genes include $M Y C, C D K 4$, and $C D K N 2$ (cell cycle and apoptosis pathways); $A U R K B$ (mitosis pathways); ATRX, BRCA1 and BRCA2 (DNA damage repair); PIK3CA, $A L K, N F 1$ and PTEN (PI3K-mTOR/RAS signaling pathways), NOTCH1-4 and $A K T 1$ (Notch signaling pathway); DLG2 (Wnt signaling pathway); SATB2 (osteoblastic differentiation); VEGFA (receptor tyrosine kinase pathway); and genes related to the IGF (insulin-like growth factor) signaling pathways [7, 12-20]. In addition to altered genes, OS also exhibits abnormal gene regulation and epigenetic mechanisms. For instance, dysfunctional long noncoding RNAs and microRNAs that modulate gene expression affect key OS features, such as apoptosis, cell cycle, proliferation, migration, invasion, and drug resistance [21-23]. Moreover, different DNA methylation patterns also seem to contribute with OS development, and higher methylation events were associated to more severe OS phenotypes [23-25]. This wide range of genetic and epigenetic variability renders OS as a very heterogeneous type of cancer, making it difficult to identify and develop novel therapies.

Researchers have proposed the existence of a specific cancer cell population responsible for cell renewal, metastasis, and drug resistance in cancers. These are cancer stem cells (CSCs), as they exhibit several hallmarks and markers in common with typical adult stem cells [26-28], and targeting their metabolism may represent a novel therapeutic strategy. The existence of these cells is a subject of controversy, due to lack of specific markers or standard identification strategies. However, the presence of CSCs has been consistently demonstrated in several cancers, such as leukemia, glioblastoma, breast, ovarian, colorectal, prostate, lung, liver, and kidney cancers [2833], and it appears that CSCs are also present in OS. Specifically, OS CSCs share similarities with mesenchymal stem cells (MSCs), which points to a probable bone-marrow MSC and/or mesenchymal progenitor cell origin for OS CSCs [10, 11, 34-37]. Studies have demonstrated that
OS CSCs have a constitutively-activated Wnt/ $\beta$-catenin signaling pathway and overexpress the stemness-related genes SOX2 and KLF4, and that CD133 can be used as a marker for OS CSC, as it is for other tumors [34, 38].

In general, the CSC phenotype exhibits high degrees of plasticity, with variations being determined by the tumor microenvironment (TME) - the stroma surrounding the growing tumor [27, 39]. Research has shown that the TME plays key roles in cancer survival and growth and is just as crucial to these processes as the cancer cells themselves [39, 40]. TME is characterized by being acidic and hypoxic-conditions that favor tumor growth and dissemination and that are shaped by the metabolic aberrancies of the cancer cells. The interplay between the tumor and its TME, which promotes tumor growth and metastasis, occurs through communication between TME-residing cells, CSCs, and bulk tumor cells, by means of secretion of high amounts of cytokines and growth factors, and through exosomes containing noncoding RNAs and other signaling molecules $[39,40]$. All these features allow cancers to create an immunosuppressive environment, where host cells are recruited and "forced" into a phenotypic change favoring immune evasion. For instance, immune cells-particularly myeloidderived suppressor cells (MDSCs), tumor-associated macrophages (TAMs) and tumor-infiltrating lymphocytes (TILs)-acquire anti-inflammatory and immunosuppressive phenotypes and are no longer capable of targeting cancer cells, while inhibiting the host's effector cells [39-41]. Similar immunological mechanisms have been described in OS, which involve TAMs with an antiinflammatory phenotype $[14,37,42,43]$. The TME is also home to other cells-including MSCs, endothelial cells and cancer-associated fibroblasts (CAFs) - , all of which have been shown to play important parts in the OS TME $[36,42,44-47]$. A specific feature of the OS TME is the "vicious cycle" between osteoclasts and cancer cells, where the latter induce resorption of the extracellular matrix by the former, causing the release of embedded growth factors, which, in turn, promotes tumor growth $[46,48]$. Furthermore, the OS TME was shown to reinforce immune evasion through overactivation of immunosuppressive pathways [49].

The standard treatment for OS includes neoadjuvant chemotherapy, which involves multiple cytotoxic agents, followed by surgical resection of the tumor-whether it be primary or secondary-, and adjuvant chemotherapy $[2,50]$. Due to the aforementioned genetic heterogeneity and instability of OS, these therapies have thus far yielded unsatisfactory results, while the plasticity of OS CSCs has, as of yet, precluded the development of CSC-aimed treatments $[2,13,15,50,51]$. Other ongoing clinical trials employ immunotherapies, attempting to overcome 
the immunosuppressive features of OS tumors and their TMEs. Although much has been elucidated in regard to the molecular pathways involved, for instance PD-1 and PD-L1, none of the candidates has reached the expected success against OS [37, 49-52]. Currently, the standard treatment for patients diagnosed with localized OS sets the 5-year survival rate at around $70 \%$. However, the 5-year survival rate for OS patients who have developed metastases has remained at $20 \%$ for the last 30 years, despite scientific progress $[3,8]$. In light of this alarming figure, the development of more efficient treatments is desperately needed, especially those aimed at metastases, as these account for the vast majority of deaths.

Targeting tumor metabolism has emerged as a prominent field of study as a consequence of greater knowledge gained in recent years regarding the unique manner through which tumors metabolize nutrients in order to survive and proliferate [53-56]. By means of such targeting, the interplay between CSC and TEM may be disrupted, thus providing novel avenues of research in the field of OS treatment. Unfortunately, while a lot of studies exist about tumor metabolism in general, there is limited research that has been performed on possible targeting strategies for OS metabolism. We thus aim at reviewing the features of tumor metabolism, in general and about OS, and propose avenues of research in dietary intervention, discussing strategies that could potentially be effective to target OS metabolism.

\section{Tumor metabolism and osteosarcoma}

Over the last decade, we have acquired a deeper understanding of the particular features of cancer cell bioenergetics. In fact, the deregulation of cellular energetics was included among the eight hallmarks of cancer in 2011 [57]. In normal cells, energy is typically obtained from glucose through the coupling of its initial breakdown (glycolysis) with the oxidation of its products in the mitochondrial oxidative phosphorylation (OXPHOS) (Fig. 1A). On the other hand, most cancer cells uncouple these two pathways and display metabolic plasticity, depending on nutrient and oxygen availabilities. Cancer cells typically utilize aerobic glycolysis as their preferred method of rapidly obtaining intermediate molecules, which serve as building blocks for their anabolic state, while producing antioxidants and high amounts of lactate $[53,58,59]$. Indeed, research shows that high cellular glucose uptake occurs in several types of cancer, including OS [60,61], and in many cases it is associated with tumor aggressiveness [58, 61-63]. In parallel, these cells fuel the tricarboxylic acid (TCA) cycle in the mitochondria with other nutrients, especially amino acids (mostly glutamine), and the intermediates from this pathway also provide precursors for biosynthesis. This allows these cells to use OXPHOS as a means of obtaining ATP, while uncoupled from glycolysis, thus maintaining high proliferative rates $[56,58,59]$ (Fig. 1B). This metabolic plasticity is especially evident among CSCs as part of their diverse phenotypes, providing them with the
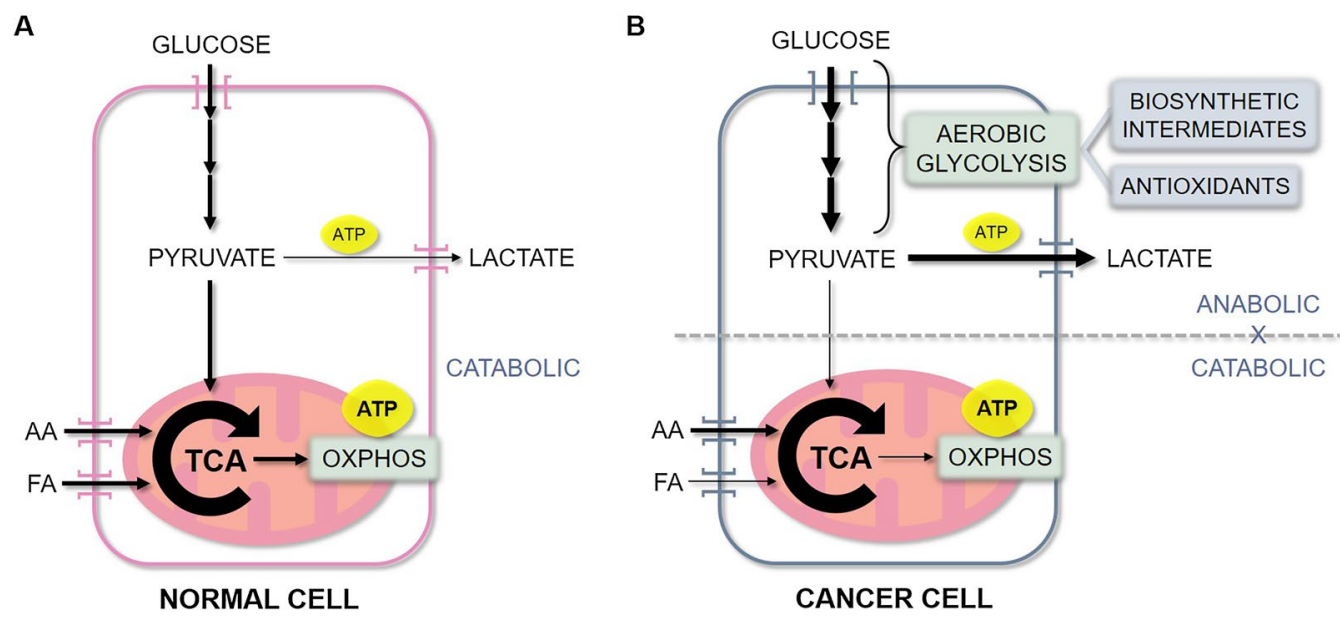

Fig. 1 Energetic metabolism of normal cells versus cancer cells. A In normal cells, energy in the form of ATP is typically obtained from glucose through the coupling of its initial breakdown (yielding a small amount of ATP-2 ATPs per glucose molecule) with the oxidation of its products in the mitochondrial TCA cycle and OXPHOS (yielding the bulk of ATP_-34 ATPs per glucose molecule). Alternatively, energy can also be obtained from fatty acids and amino acids, which are fueled into the TCA cycle and OXPHOS. B Cancer cells, on the other hand, uncouple the anabolic glycolytic pathway from the catabolic TCA cycle and OXPHOS. They increase glucose uptake, utilizing aerobic glycolysis as the main source of biosynthetic molecules, while producing antioxidants and high amounts of lactate. In parallel, these cells fuel the TCA cycle with amino acids and, to a lesser extent, fatty acids, allowing these cells to use OXPHOS as a means of obtaining the bulk of ATP, while uncoupled from glycolysis. AA: Amino acids; FA: Fatty acids; TCA: Tricarboxylic acid cycle; OXPHOS: Oxidative phosphorylation; ATP: Adenosine triphosphate 
ability of adapting to stresses, such as nutrient deprivation, hypoxia, and the presence of antitumor drugs [64, 65]. While these features of cancer cell bioenergetics seem to apply to OS as well, the exact characteristics of the OS metabolism remain to be elucidated. For instance, studies have shown that, although metabolically plastic, OS CSCs follow this trend and preferably utilize the glycolytic pathway, with downregulation of the TCA cycle and OXPHOS pathways [66, 67].

It is important to note that the metabolic reprogramming observed in tumor cells is not a passive event, nor a mere consequence of tumor development. Rather, it is a deliberate and required process, where tumor growthrelated pathways and cellular metabolism are intimately connected [56]. For example, mutations in the TCA cycle enzymes isocitrate dehydrogenases- 1 and -2 can directly contribute to tumorigenesis in several cancers, including glioma, OS, and chondrosarcoma, by altering the function of other enzymes, which either degrade protumorigenic factors or regulate methylation of histones or DNA $[68,69]$. Other metabolism-related pathways are direct targets of oncogene and defective tumor suppressor gene products. For example, the PI3K/Akt-mTOR pathway, which is typically altered in cancers-including OS-, upregulates cellular glucose uptake, while oncogenes $c-M Y C$ and hypoxia-inducible factor-1 (HIF-1) upregulate glycolytic enzymes [59, 70-72]. Increased levels of insulin-like growth factor-1 (IGF-1) and its receptor generally occur in OS and in other cancers, and also activate the PI3K/Akt-mTOR pathway, promoting tumor growth [73-75].

The metabolic reprogramming that occurs in cancers in general, and in OS as well [43], also influences the host's immune response, representing a key contributor to the creation of an immunosuppressive TME [40, 41]. The host's effector cells have similar metabolic requirements as tumor cells, and thus compete with them for nutrients in the TME, especially glucose and glutamine. This competition for nutrients, together with the lactate-induced acidosis, make the TME favorable for TILs, TAMs and MDSCs, and unsuitable for effector cells, thus promoting immune evasion. TILs and TAMs have anti-inflammatory phenotypes and either secrete or induce factors that promote immunosuppression and tumor invasion, such as interleukin-10 (Il-10), TGF- $\beta$, PD-1, reactive oxygen species (ROS) and arginase [40, 43, 49, 65, 76-80] (Fig. 2).

Given the clear importance of tumor cell bioenergetics, various cancer metabolism-targeting strategies-consisting of drugs directed at specific metabolic components and pathways-have been explored in both preclinical and clinical studies over the last several years $[55,81,82]$. The most studied are the ones targeting

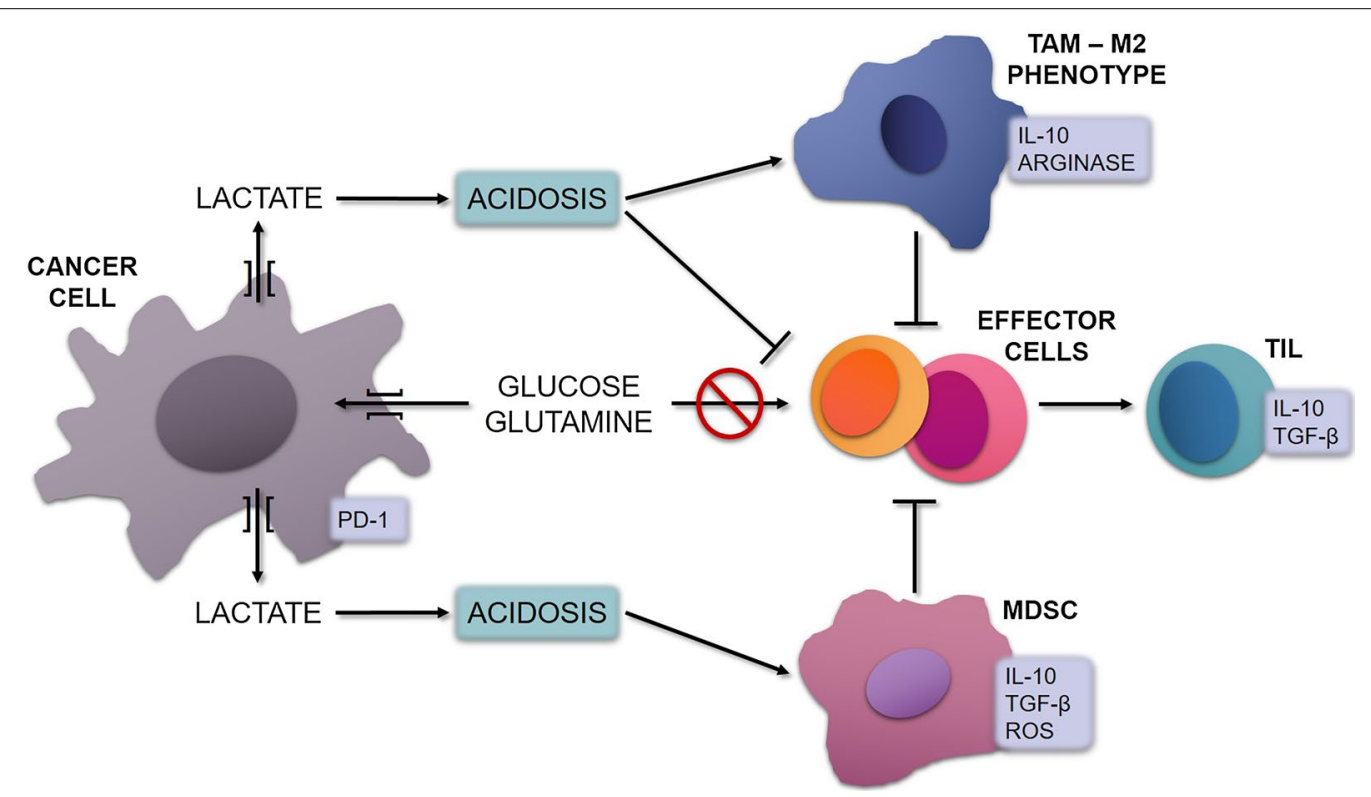

Fig. 2 Cancer cell metabolism induces immunosuppression in the TME. Cancer cells compete with the host's effector cells for nutrients. Their dysregulated metabolism leads to increased uptake of glucose and glutamine, depleting the effector cells from these nutrients, thus hindering their activity. Additionally, cancer cells release high amounts of lactate into the extracellular space, resulting in acidosis. This, in turn, makes the TME favorable for TILs, TAMs and MDSCs, and unsuitable for effector cells. TAMs are induced to express an M2 anti-inflammatory phenotype, secreting II-10 and arginase. TILs also exhibit an anti-inflammatory phenotype, secreting II-10 and TGF- $\beta$, while MDSC secrete II-10, TGF- $\beta$ and ROS. These factors further inhibit effector cells, promoting immunosuppression. TAM: Tumor-associated macrophages; IL-10: Interleukin-10; TGF- $\beta$ : Transforming growth factor- $\beta$; ROS: Reactive oxygen species 
enzymes involved in the glycolytic pathways, such as 2-deoxy-D-glucose, oleanolic acid, and 3-bromopyruvate, as reviewed in [53], 55. Another important group includes inhibitors of transporter molecules, especially those involved in glucose and glutamine uptake, as well as lactate transport, reviewed in [55]. Drugs interfering in pathways that regulate tumor cell metabolism are also being studied, including c-MYC, mTOR and PI3K/ Akt inhibitors, and AMPK activators, reviewed in [82]. A few of these studies were carried out on OS. For example, preclinical investigations have shown that metforminan AMPK inducer, which inhibits OXPHOS and causes oxidative stress-was capable of inducing apoptosis of OS cell lines, as well as preventing tumor growth in xenograft OS mouse models $[83,84]$. In another study, a glutaminase inhibitor was utilized in combination with metformin in a xenograft OS mouse model, and the combination was more successful than treatments alone and non-treated controls in inhibiting primary tumor growth, as well as in preventing metastases [85]. Furthermore, glycolytic activities were reduced in OS cell lines and in a xenograft OS mouse model with the use of a synthetic oleanolic acid derivative-which inhibits pyruvate kinase, a glycolytic enzyme-, resulting in tumor growth inhibition [86]. However, despite reaching pre-clinical success, most of the proposed therapies have not thus far been approved as anticancer drugs for humans.

A controlled diet-based approach may represent an attractive and inexpensive alternative to target the metabolism in cancer that clinicians could use in combination with existing treatment regimens for their patients. Of course, patients should avoid adopting diet regimens without doctors' supervision. The most studied diet-based approaches to treat cancer are: caloric restriction, fasting, and the ketogenic diet, and the use of dietary supplements. However, thus far, these diets have not been analyzed in an OS context. The following section will review what investigators have uncovered on the use of these dietary approaches as potential cancer treatments in general, proposing to promote these avenues of research in the field of OS.

\section{Dietary interventions that may target osteosarcoma \\ Caloric restriction diet}

The caloric restriction (CR) diet typically refers to a continuous reduction of normal daily recommended calorie intake by approximately $30 \%$, with proportional reduction of all macronutrients, while maintaining adequate amounts of vitamins and minerals, without developing malnutrition. It has been widely studied and applied to prevent or reverse obesity and aging [73, 87, 88]. However, there are concerns regarding patient tolerance to this diet, especially considering that it causes weight loss and cancer patients may be prone to developing cachexia. Therefore, clinical studies that utilize this diet in cancer patients always include careful nutritional monitoring $[54,87]$.

The main mechanism of action for its antitumor effects is through inhibition of IGF-1. As a result, the IGF-1/ PI3K/Akt signaling pathways are repressed, thus inducing apoptosis and reducing angiogenesis, cell cycle progression, and metastasis $[73,89,90]$. Additionally, AMP-activated protein kinase (AMPK) is activated, which, in turn, also inhibits the PI3K/Akt-mTOR pathway, and, consequently, the anabolic pathways [87].

Although dietary interventions against cancer have not been extensively explored, the antitumor effects of $C R$ have been confirmed in a number of preclinical investigations-none, however, for OS. In mice models for cancer, colon cancers showed reduced tumor volumes when compared to controls [91], while prostate [92], breast [93] and pancreatic [94] cancers were prevented. In a rat model for breast cancer, not only did CR prevent tumor development, but it also prevented its progression, with the demonstration of an inhibitory effect on CSCs [95]. In addition, CR has been studied as an adjuvant to standard chemotherapy and radiation therapy, demonstrating the ability to improve treatment results. The addition of CR to ganitumab (an anti-IGF-1R drug) improved tumor reduction in prostate cancer mice when compared to the drug alone, with increased apoptosis and reduced cell proliferation [96]. In a triple-negative breast cancer mouse model, CR reversed treatment-induced inflammation from cisplatin through IGF-1 modulation, thereby reducing drug resistance [97]. CR was also shown to improve radiation therapy treatment in two aggressive breast cancer models, delaying metastasis and tumor growth, and increasing survival in comparison to the radiation therapy alone [98]. Another study using a murine triple-negative breast cancer model demonstrated that CR was capable of decreasing the number of intratumoral TILs and increasing the number of effector cells after radiation therapy [99].

Given the increased levels of IGF-1 and the strongly activated PI3K/Akt-mTOR pathway observed in OS [60, $72,75], C R$ could potentially be effective against this tumor. It would be, therefore, interesting to study the effects of CR on development and metastasis of OS.

\section{Fasting diet}

Fasting is a complete deprivation of nutrients during a specific period of time, with no food intake-only water. However, there are different versions of clinically-feasible fasting. The most common are the fast-mimicking diets (FMDs), which can be performed with varied protocols. 
For instance, FMDs can be followed by means of cycles of restricted access to food (very low caloric intake-typically 300 to $1100 \mathrm{kcal}$ a day-, for example, five consecutive days once a month, for 3 months) [100], or by means of intermittent fasting (IF), which involves a specific number of hours of complete nutrient deprivation cycled with a period of unrestricted access to food (for example, $16-18$ h daily) [100-102].

The rationale for using fasting as an antitumor therapy is to limit the amount of glucose and amino acids (AA) available to cancer cells, thereby disturbing their metabolism. Mechanistically, the effects of fasting regimes seem to be similar to those of CR, in that IGF-1 is reduced and AMPK is activated, inhibiting the PI3K/Akt-mTOR pathway. Additionally, due to the restriction of glucose, aerobic glycolysis, on which tumors rely for proliferation and immunosuppression, is also inhibited [17, 101, 103]. Moreover, the limitation of AA availability also impacts cancers, given that in general, they require large amounts of AA for cell proliferation and survival. Although they are capable of synthesizing non-essential AA intracellularly, they still require exogenous sources of both essential and non-essential AA, as the produced amount is insufficient for the cell requirements [104, 105]. Therefore, disturbing AA metabolism is yet another mechanism of action of fasting.

Fasting has successfully inhibited cancer cells in a few preclinical studies, although none of these studies focused on OS. For instance, an astrocytoma mouse model received an IF protocol ( $24 \mathrm{~h}$ in alternate days) and exhibited significantly smaller tumors with significantly higher survival rates, relative to controls [106]. Similarly, a colorectal cancer mouse model received an IF regime and showed significantly slowed tumor growth. Interestingly, the authors verified that the diet suppressed M2 polarization of TAMs, pointing to a more favorable immune response switching [107]. On the other hand, IF (24 h, twice a week) did not exert antitumor effects on a prostate cancer mouse model [108]. A colorectal cancer mouse model was also used to evaluate the effect of an FMD, with two weekly cycles, where each week was divided into three parts: day 1 with $50 \%$ of normal caloric intake, days $2-3$ with $10 \%$ of normal caloric intake, and days 4-7 with normal food intake. The results showed, once again, a slower progression, with inhibition of proliferation and demonstration of a significantly reduced glucose intake [109]. Another study demonstrated that two weekly cycles of two-day fasting regimes inhibited colon cancer growth in mice in comparison to controls, while also demonstrating that cells switched from a glycolysis-based metabolism to an oxidative phosphorylation-based metabolism. In this same study, the authors also tested the effect of oxaliplatin-a standard chemotherapeutic agent-alone and in combination with fasting and verified that the combination therapy had the best results [103]. Other studies also evaluated fasting in combination with other treatments. For instance, in a lung cancer mouse model, animals underwent two cycles of $48 \mathrm{~h}$-fasting and one cycle of $24 \mathrm{~h}$-fasting in combination with a PD-1 immune checkpoint blockade. Results indicated that the combination treatment had a synergistic effect, inhibiting tumor progression and metastasis more effectively than untreated controls or either diet or anti-PD-1 alone [110].

Importantly, short-term fasting ( $48-60 \mathrm{~h}$ pre- and postchemotherapy or radiation therapy) was demonstrated to induce differential stress resistance both in animal and human studies. By means of this mechanism, normal cells acquire a protected and slow-division state against the toxic effects of chemotherapy or radiation therapy, or other toxic agents, while cancer cells remain susceptible. Based on this lower toxicity to the host's cells, in many instances, fasting allows the employment of higher and, thus, more effective, treatment doses [101,111-116].

As mentioned, studies about the effects of fasting on development and treatment for OS are missing. Yet, given that OS relies heavily on glycolysis, as well as on the IGF-1/PI3K/AKT signaling pathways $[60,66,67,75]$, fasting approaches could also be a promising tool against OS. Moreover, the metabolism of many AA was shown to be upregulated in OS, especially alanine, aspartate, glutamate, arginine, proline, cysteine and methionine [66]. Fasting could, therefore, also impact AA metabolism in OS cells, contributing to the other anticancer effects. Future preclinical studies are needed to evaluate the effectiveness of this approach for treatment of OS.

\section{Ketogenic diet}

The ketogenic diet (KD) is defined as a high-fat, moderate-protein, and low-carbohydrate diet, typically with a 4:1 ratio of fat to protein and carbohydrates. Systemically, the low glucose concentrations inhibit insulin and activate glucagon secretion, and the body is forced into a ketogenic state, whereby liver cells oxidize fatty acids, producing ketone bodies-namely acetoacetate, $\beta$-hydroxybutyrate and acetone. These enter the circulation and are distributed to other tissues, serving as fuel for cell metabolism, after entering the TCA cycle. This diet was initially formulated to treat epilepsy and is currently also being used to treat obesity [117-119]. The KD is usually well-tolerated, although it may lead to mild side-effects, such as lethargy and nausea; however, if adequately monitored, they are easily avoided $[54,120,121]$.

The very low amount of glucose ingestion due to $\mathrm{KD}$ blocks the cells' ability -including cancer cells'-of using the glycolytic pathway. This hinders the cancer's main 
source of building blocks for proliferation, thus leading to a lower proliferative rate. The limitation of the glycolytic pathway also impacts one of the most important sources of antioxidants, leading to higher oxidative stress, as cancer cells produce high amounts of ROS, thus potentially causing apoptosis $[117,122,123]$. Similar to the previously mentioned diets, the KD is also capable of reducing IGF-1 levels, which induces activation of AMPK, inhibiting the PI3K/Akt-mTOR pathway [119, 124].

A possible limitation of reducing glucose intake is the fact that it could further hamper the host's defense, as effector cells require glucose to initiate an immunologic response. However, it has been demonstrated that effector cells are still able to mount an immune response despite low amounts of glucose. Although the reason behind this is unknown, it was hypothesized that these cells could utilize ketone bodies instead of glucose and still maintain their metabolic activities [125].

Compared to CR and fasting, there are more animal studies on the antitumor effects of KD, especially for brain tumors. However, none of these studies were performed on OS. Because of the blood-brain barrier, brain tissue cannot metabolize fatty acids; thus, the brain relies on glucose as its main source of energy. In the absence of glucose, brain cells are able to metabolize ketone bodies, while brain tumors likely have defective ketone metabolisms and rely mostly on a glycolytic metabolism, therefore rendering them more sensitive to a $\operatorname{KD}[126,127]$. In glioblastoma mouse models, KD significantly slowed tumor progression and increased survival rates when compared to normal diet $[125,128,129]$. Another study using a glioma mouse model interestingly found that the KD was able to influence the TME, by downregulating hypoxia-related markers, which favor tumor progression, in addition to downregulating angiogenesis-related factors [130]. KD was effective in reducing tumor growth and improving survival rates in neuroblastoma mice [131]; however, it was unsuccessful in eliciting antitumor effects in medulloblastoma mice [132]. Lussier et al. analyzed the immunologic effects of the KD's impact on the TME of gliomas in a mouse model and found that it was able to promote phenotypic changes in the TILs. Tumors treated with KD showed an increased CD4+ T cell population and a reduced regulatory $\mathrm{T}$ cell population when compared to controls, while reducing expression of PD-1 on $\mathrm{CD} 8+\mathrm{T}$ cells, thus opposing immunosuppression [125]. The KD produced significantly smaller tumors in a squamous cell carcinoma mouse model [133], as well as in breast [123, 134], prostate [135], colorectal [136, 137], pancreatic [80], and gastric [138] cancer mouse models, relative to controls. While a $\mathrm{KD}$ also produced these antitumor effects in a liver cancer mouse model [139], it failed to do so in another study by the same group, where the dietary intervention took place when tumors were in a later stage, suggesting that the $\mathrm{KD}$, in this case, had a more preventive than therapeutic action [140]. The beneficial effects of KD may also be cancer-specific, since studies on a mouse model of melanoma showed that KD enhanced tumor growth [141]. In other studies, KD was evaluated in combination with other treatments. For instance, KD synergized with radiation therapy [142] and chemotherapy [143, 144], leading to significantly smaller gliomas and prolonged survival in mice in comparison to stand-alone treatments and controls. Similar effects were observed in neuroblastoma [145] and breast cancer [146] mouse models treated with KD and chemotherapy, as well as in a lung cancer mouse model treated with KD, chemotherapy and radiation therapy [147].

Fewer studies analyzing the effects of KD have been conducted in humans, most of which had the primary focus of determining feasibility and safety. These studies concluded that KD is overall safe and feasible for different cancer patients, in most cases improving quality of life; however, none showed antitumor effects of KD as standalone treatment [148-156]. An interesting find was a significant decline in the amount of lactate in head and neck cancers of patients treated with KD compared to those with normal diets, which may confirm the potential to counteract immunosuppression [157].

As with the aforementioned diets, the KD has yet to have its antitumor effects tested on OS. However, it does have potential to be effective in this regard, as the reduced amount of glucose impacts the glycolytic pathways, as well as the IGF-1/PI3K/AKT signaling pathways, which have been shown to be enhanced in OS $[60,66,67$, 75]. It could, therefore, be interesting to develop new preclinical studies to test this diet on OS.

\section{Dietary supplements: quercetin}

Dietary supplements could also be used in addition to, or in alternative to, dietary modifications $[158,159]$. However, no dietary supplements have been approved as anticancer therapies in the United States. This is due, in part, to the observational nature of the available studies about dietary supplements, as well as the lack of regulation for their use $[159,160]$. Among the various dietary supplements available, quercetin-largely used worldwide and found in fruits, vegetables, tea, and wine-has shown some potential. Quercetin is a bioactive flavonoid with antioxidant, antiestrogenic, and antiproliferative effects that may be at the basis of its therapeutic properties [161]. Several in vitro and in vivo preclinical studies have been conducted regarding its anticancer effects, as reviewed in $[162,163]$ and shown in [164]. Although the exact mechanisms of Quercetin anticancer properties are not clear, they seem to occur via modulation of VEGF, 
apoptosis, PI3K/Akt/mTOR, and Wnt/ $\beta$-catenin signaling pathways $[162,163]$-all of which are affected in OS. Indeed, quercetin has consistently shown effectiveness against $O S$ in vitro and in vivo. For instance, studies have shown that Quercetin induces inhibition of proliferation, cell cycle arrest, and apoptosis of MG-63 [165, 166], U2OS, Saos-2 [166], HOS [167], and 143B [168] cells. Additionally, $\mathrm{Wu}$ et al. showed that quercetin induces autophagy of MG-63 cells in vitro and in vivo [169]. Lan et al. demonstrated that quercetin attenuated cell migration and invasion, with downregulation of HIF- $1 \alpha$, VEGF, MMP2, and MMP9 expression on HOS and MG-63 cells, when compared to vehicle control. They also verified reduction in the lung metastases in OS xenograft models [170]. While these studies indicate that Quercetin may have some effects on OS, additional preclinical studies and randomized clinical trials are needed to confirm its anticancer efficacy. Considering the significantly high doses, well above the normal dietary intake, that may be required to achieve the anticancer effects, safety considerations should be carefully assessed $[171,172]$.

\section{Conclusions and future perspectives}

Considering the importance of the aberrant bioenergetics of cancer to its progression and aggressiveness, targeting tumor metabolism may represent a promising strategy to treat cancer in general, and may represent an interesting avenue of research as a novel approach to treat OS. Although, to date, dietary approaches have not been evaluated as treatments for OS, it would be interesting to initiate a series of preclinical and clinical investigations to explore their impact on OS cells, uncovering possible mechanisms of action and novel therapeutic strategies. These studies should aim at testing the effects of different diets or diet supplements on CSCs metabolism and their interplay with the TME. Although CR, fasting and ketogenic diets, and the supplemental use of quercetin are overall well-tolerated by patients $[100,101,155,171$, 173], it would be necessary to verify safety along with efficacy.

Moreover, human diets in general appear to be more effective when used in combination with other anticancer treatments [54, 101, 174]. One of the reasons why tumors are resistant to anticancer therapies is the fact that they exhibit multiple redundant pathways to promote growth, survival, and metastasis, which renders single-target therapies ineffective. This holds especially true for OS, which is highly heterogeneous genetically and phenotypically. Therefore, the key to improving success in OS could be the use of combination therapies: a dietary approach could likely sensitize OS cells to another antitumor therapy. For example, a recent study in pediatric patients with acute lymphoblastic leukemia showed improvement of response to chemotherapy when combined with CR [175].

In conclusion, it would be interesting to include dietary interventions as both stand-alone or combination therapies as subject of future avenues of research in OS. Very little is known at the moment, and therefore extensive preclinical in vitro and in vivo investigations should be performed prior to clinical trials.

\section{Abbreviations \\ OS: Osteosarcoma; OXPHOS: Oxidative phosphorylation; IGF: Insulin-like growth factor; CSC: Cancer stem cell; MSC: Mesenchymal stem cell; TME: Tumor microenvironment; MDSC: Myeloid-derived suppressor cell; TAM: Tumor-associated macrophage; TIL: Tumor-infiltrating lymphocyte; CAF: Cancer-associated fibroblast; PD-1: Programmed cell death protein-1; PD-L1: Programmed cell death protein-1 ligand; IDO: Indoleamine dioxygenase; TGF- $\beta$ : Transforming growth factor-beta; STAT3: Signal transducer and activator of transcription 3; VEGF: Vascular endothelial growth factor; IL-10: Interleukin 10; TCA: Tricarboxylic acid; AA: Amino acid; FA: Fatty acid; HIF-1: Hypoxia- inducible factor-1; ROS: Reactive oxygen species; CR: Caloric restriction; AMPK: AMP-activated protein kinase; IGF-1R: Insulin-like growth factor receptor; FMD: Fasting-mimicking diet; IF: Intermittent fasting; KD: Ketogenic diet.}

\section{Acknowledgements}

Not applicable.

\section{Authors' contributions}

TCL and Gl participated in the conception and design of the manuscript. TCL participated in drafting the article and preparing the figures. RJW, KRW and GI provided critical review of the manuscript and figures. TCL, RJW, KRW and Gl have all reviewed and approved the final version of the manuscript.

Funding

NCI/NIH Grant \# R21 CA208618 to Gl.

Availability of data and materials

Not applicable.

\section{Declarations}

Ethics approval and consent to participate

Not applicable.

\section{Consent for publication \\ Not applicable.}

\section{Competing interests}

The authors declare that they have no competing interests.

\section{Author details}

${ }^{1}$ Department of Oral and Craniofacial Sciences, University of Pittsburgh School of Dental Medicine, Pittsburgh, PA, USA. ${ }^{2}$ Center for Craniofacial Regeneration, University of Pittsburgh School of Dental Medicine, Pittsburgh, PA, USA. ${ }^{3}$ Department of Orthopaedic Surgery, University of Pittsburgh Medical Center, Pittsburgh, PA, USA. ${ }^{4}$ Department of Pharmacology \& Chemical Biology, University of Pittsburgh School of Medicine, Pittsburgh, PA, USA. ${ }^{5}$ Hillman Cancer Center, University of Pittsburgh Medical Center, Pittsburgh, PA, USA. ${ }^{6}$ Department of Periodontics and Preventive Dentistry, University of Pittsburgh School of Dental Medicine, Pittsburgh, PA, USA. 'Department of Medicine, Division of Hematology and Oncology, University of Pittsburgh School of Medicine, Pittsburgh, PA, USA. ${ }^{8}$ McGowan Institute for Regenerative Medicine, University of Pittsburgh, Pittsburgh, PA, USA. 
Received: 4 August 2021 Accepted: 12 October 2021

Published online: 29 October 2021

\section{References}

1. Mirabello L, Troisi RJ, Savage SA. International osteosarcoma incidence patterns in children and adolescents, middle ages and elderly persons. Int J Cancer. 2009;125(1):229-34.

2. Luetke A, Meyers PA, Lewis I, Juergens H. Osteosarcoma treatmentwhere do we stand? A state of the art review. Cancer Treat Rev. 2014;40(4):523-32.

3. Berner K, Johannesen TB, Berner A, Haugland HK, Bjerkehagen B, Bohler $P J$, et al. Time-trends on incidence and survival in a nationwide and unselected cohort of patients with skeletal osteosarcoma. Acta Oncol. 2015;54(1):25-33.

4. Lindsey BA, Markel JE, Kleinerman ES. Osteosarcoma overview. Rheumatol Ther. 2017:4(1):25-43.

5. Gorlick R, Khanna C. Osteosarcoma. J Bone Miner Res. 2010;25(4):683-91.

6. Savage SA, Mirabello L. Using epidemiology and genomics to understand osteosarcoma etiology. Sarcoma. 2011;2011:548151.

7. Czarnecka AM, Synoradzki K, Firlej W, Bartnik E, Sobczuk P, Fiedorowicz M, et al. Molecular biology of osteosarcoma. Cancers. 2020;12(8):2130.

8. Smeland S, Bielack SS, Whelan J, Bernstein M, Hogendoorn P, Krailo MD, et al. Survival and prognosis with osteosarcoma: outcomes in more than 2000 patients in the EURAMOS-1 (European and American Osteosarcoma Study) cohort. Eur J Cancer. 2019;109:36-50.

9. Rickel K, Fang F, Tao J. Molecular genetics of osteosarcoma. Bone. 2017;102:69-79.

10. Walkley CR, Qudsi R, Sankaran VG, Perry JA, Gostissa M, Roth SI, et al. Conditional mouse osteosarcoma, dependent on p53 loss and potentiated by loss of Rb, mimics the human disease. Genes Dev. 2008;22(12):1662-76.

11. Lin PP, Pandey MK, Jin F, Raymond AK, Akiyama H, Lozano G. Targeted mutation of p53 and Rb in mesenchymal cells of the limb bud produces sarcomas in mice. Carcinogenesis. 2009:30(10):1789-95.

12. Bousquet M, Noirot C, Accadbled F, Sales de Gauzy J, Castex MP Brousset $\mathrm{P}$, et al. Whole-exome sequencing in osteosarcoma reveals important heterogeneity of genetic alterations. Ann Oncol. 2016;27(4):738-44.

13. Zhao J, Dean DC, Hornicek FJ, Yu X, Duan Z. Emerging next-generation sequencing-based discoveries for targeted osteosarcoma therapy. Cancer Lett. 2020;474:158-67.

14. Wu CC, Beird HC, Andrew Livingston J, Advani S, Mitra A, Cao S, et al. Immuno-genomic landscape of osteosarcoma. Nat Commun. 2020;11(1):1008.

15. Gianferante DM, Mirabello L, Savage SA. Germline and somatic genetics of osteosarcoma-connecting aetiology, biology and therapy. Nat Rev Endocrinol. 2017;13(8):480-91.

16. Heng L, Jia Z, Bai J, Zhang K, Zhu Y, Ma J, et al. Molecular characterization of metastatic osteosarcoma: differentially expressed genes, transcription factors and microRNAs. Mol Med Rep. 2017;15(5):2829-36.

17. Sun J, Xu H, Qi M, Zhang C, Shi J. Identification of key genes in osteosarcoma by metaanalysis of gene expression microarray. Mol Med Rep. 2019;20(4):3075-84.

18. Yang $Y$, Zhang $Y$, Qu X, Xia J, Li D, Li X, et al. Identification of differentially expressed genes in the development of osteosarcoma using RNA-seq. Oncotarget. 2016;7(52):87194-205.

19. Machado I, Navarro S, Picci P, Llombart-Bosch A. The utility of SATB2 immunohistochemical expression in distinguishing between osteosarcomas and their malignant bone tumor mimickers, such as Ewing sarcomas and chondrosarcomas. Pathol Res Pract. 2016;212(9):811-6.

20. Conner JR, Hornick JL. SATB2 is a novel marker of osteoblastic differentiation in bone and soft tissue tumours. Histopathology. 2013;63(1):36-49.

21. Wang JY, Yang Y, Ma Y, Wang F, Xue A, Zhu J, et al. Potential regulatory role of IncRNA-miRNA-mRNA axis in osteosarcoma. Biomed Pharmacother. 2020;121:109627.

22. Xie L, Yao Z, Zhang Y, Li D, Hu F, Liao Y, et al. Deep RNA sequencing reveals the dynamic regulation of miRNA, IncRNAs, and mRNAs in osteosarcoma tumorigenesis and pulmonary metastasis. Cell Death Dis. 2018;9(7):772.

23. de Azevedo JWV, de Medeiros Fernandes TAA, Fernandes JV Jr, de Azevedo JCV, Lanza DCF, Bezerra CM, et al. Biology and pathogenesis of human osteosarcoma. Oncol Lett. 2020;19(2):1099-116.

24. Rosenblum JM, Wijetunga NA, Fazzari MJ, Krailo M, Barkauskas DA, Gorlick R, et al. Predictive properties of DNA methylation patterns in primary tumor samples for osteosarcoma relapse status. Epigenetics. 2015;10(1):31-9.

25. Tian W, Li Y, Zhang J, Li J, Gao J. Combined analysis of DNA methylation and gene expression profiles of osteosarcoma identified several prognosis signatures. Gene. 2018;650:7-14.

26. Gupta PB, Chaffer CL, Weinberg RA. Cancer stem cells: mirage or reality? Nat Med. 2009;15(9):1010-2.

27. Vermeulen L, de Sousa e Melo F, Richel DJ, Medema JP. The developing cancer stem-cell model: clinical challenges and opportunities. Lancet Oncol. 2012;13(2):e83-9.

28. Marzagalli M, Fontana F, Raimondi M, Limonta P. Cancer stem cells-key players in tumor relapse. Cancers. 2021;13(3):376.

29. Gao X, Dong QZ. Advance in metabolism and target therapy in breast cancer stem cells. World J Stem Cells. 2020;12(11):1295-306.

30. Kim HJ, Park JW, Lee JH. Genetic architectures and cell-of-origin in glioblastoma. Front Oncol. 2020;10:615400.

31. Pagotto S, Colorito ML, Nicotra A, Apuzzo T, Tinari N, Protasi F, et al. A perspective analysis: microRNAs, glucose metabolism, and drug resistance in colon cancer stem cells. Cancer Gene Ther. 2021. https://doi. org/10.1038/s41417-021-00298-5.

32. Corro C, Moch H. Biomarker discovery for renal cancer stem cells. J Pathol Clin Res. 2018;4(1):3-18.

33. Sabini C, Sorbi F, Cunnea P, Fotopoulou C. Ovarian cancer stem cells: ready for prime time? Arch Gynecol Obstet. 2020;301(4):895-9.

34. Abarrategi A, Tornin J, Martinez-Cruzado L, Hamilton A, Martinez-Campos E, Rodrigo JP, et al. Osteosarcoma: cells-of-origin, cancer stem cells, and targeted therapies. Stem Cells Int. 2016;2016:3631764.

35. Zhang D, Zhao Q, Sun H, Yin L, Wu J, Xu J, et al. Defective autophagy leads to the suppression of stem-like features of CD271(+) osteosarcoma cells. J Biomed Sci. 2016;23(1):82.

36. Zheng Y, Wang G, Chen R, Hua Y, Cai Z. Mesenchymal stem cells in the osteosarcoma microenvironment: their biological properties, influence on tumor growth, and therapeutic implications. Stem Cell Res Ther. 2018;9(1):22.

37. Hu C, Liu C, Tian S, Wang Y, Shen R, Rao H, et al. Comprehensive analysis of prognostic tumor microenvironment-related genes in osteosarcoma patients. BMC Cancer. 2020;20(1):814.

38. Martins-Neves SR, Corver WE, Paiva-Oliveira Dl, van den Akker BE, Briaire-de-Bruijn IH, Bovee JV, et al. Osteosarcoma stem cells have active Wnt/beta-catenin and overexpress SOX2 and KLF4. J Cell Physiol. 2016;231(4):876-86.

39. Augustin RC, Delgoffe GM, Najjar YG. Characteristics of the tumor microenvironment that influence immune cell functions: hypoxia, oxidative stress, metabolic alterations. Cancers. 2020;12(12):3802.

40. Kaymak I, Williams KS, Cantor JR, Jones RG. Immunometabolic interplay in the tumor microenvironment. Cancer Cell. 2021:39(1):28-37.

41. Labani-Motlagh A, Ashja-Mahdavi M, Loskog A. The tumor microenvironment: a milieu hindering and obstructing antitumor immune responses. Front Immunol. 2020;11:940.

42. Zhou Y, Yang D, Yang Q, Lv X, Huang W, Zhou Z, et al. Single-cell RNA landscape of intratumoral heterogeneity and immunosuppressive microenvironment in advanced osteosarcoma. Nat Commun. 2020;11(1):6322.

43. Heymann MF, Lezot F, Heymann D. The contribution of immune infiltrates and the local microenvironment in the pathogenesis of osteosarcoma. Cell Immunol. 2019;343:103711.

44. Yang C, Tian Y, Zhao F, Chen Z, Su P, Li Y, et al. Bone microenvironment and osteosarcoma metastasis. Int J Mol Sci. 2020;21 (19):6985.

45. LiYS, Liu Q, Tian J, He HB, Luo W. Angiogenesis process in osteosarcoma: an updated perspective of pathophysiology and therapeutics. Am J Med Sci. 2019;357(4):280-8.

46. Corre I, Verrecchia F, Crenn V, Redini F, Trichet V. The osteosarcoma microenvironment: a complex but targetable ecosystem. Cells. 2020:9(4):976 
47. Wang YM, Wang W, Qiu ED. Osteosarcoma cells induce differentiation of mesenchymal stem cells into cancer associated fibroblasts through Notch and Akt signaling pathway. Int J Clin Exp Pathol. 2017;10(8):8479-86

48. Lamoureux F, Richard P, Wittrant $Y$, Battaglia S, Pilet $P$, Trichet $V$, et al. Therapeutic relevance of osteoprotegerin gene therapy in osteosarcoma: blockade of the vicious cycle between tumor cell proliferation and bone resorption. Cancer Res. 2007;67(15):7308-18.

49. Chen C, Xie L, Ren T, Huang Y, Xu J, Guo W. Immunotherapy for osteosarcoma: Fundamental mechanism, rationale, and recent breakthroughs. Cancer Lett. 2021;500:1-10.

50. Duffaud F. Role of TKI for metastatic osteogenic sarcoma. Curr Treat Options Oncol. 2020;21(8):65.

51. Smrke A, Anderson PM, Gulia A, Gennatas S, Huang PH, Jones RL. Future directions in the treatment of osteosarcoma. Cells. 2021;10(1):172.

52. Keung EZ, Burgess M, Salazar R, Parra ER, Rodrigues-Canales J, Bolejack $\mathrm{V}$, et al. Correlative analyses of the SARC028 trial reveal an association between sarcoma-associated immune infiltrate and response to pembrolizumab. Clin Cancer Res. 2020;26(6):1258-66.

53. Lasche M, Emons G, Grundker C. Shedding new light on cancer metabolism: a metabolic tightrope between life and death. Front Oncol. 2020;10:409.

54. Gray A, Dang BN, Moore TB, Clemens R, Pressman P. A review of nutrition and dietary interventions in oncology. SAGE Open Med. 2020;8:2050312120926877.

55. Abdel-Wahab AF, Mahmoud W, Al-Harizy RM. Targeting glucose metabolism to suppress cancer progression: prospective of anti-glycolytic cancer therapy. Pharmacol Res. 2019;150:104511.

56. Ward PS, Thompson CB. Metabolic reprogramming: a cancer hallmark even warburg did not anticipate. Cancer Cell. 2012;21(3):297-308.

57. Hanahan D, Weinberg RA. Hallmarks of cancer: the next generation. Cell. 2011;144(5):646-74

58. Gatenby RA, Gillies RJ. Why do cancers have high aerobic glycolysis? Nat Rev Cancer. 2004;4(11):891-9.

59. Vander Heiden MG, DeBerardinis RJ. Understanding the intersections between metabolism and cancer biology. Cell. 2017;168(4):657-69.

60. Collantes M, Martinez-Velez N, Zalacain M, Marrodan L, Ecay M, GarciaVelloso MJ, et al. Assessment of metabolic patterns and new antitumoral treatment in osteosarcoma xenograft models by [(18)F]FDG and sodium [(18)F]fluoride PET. BMC Cancer. 2018;18(1):1193.

61. Song Z, Pearce MC, Jiang Y, Yang L, Goodall C, Miranda CL, et al. Delineation of hypoxia-induced proteome shifts in osteosarcoma cells with different metastatic propensities. Sci Rep. 2020;10(1):727.

62. Mochiki E, Kuwano H, Katoh H, Asao T, Oriuchi N, Endo K. Evaluation of 18F-2-deoxy-2-fluoro-D-glucose positron emission tomography for gastric cancer. World J Surg. 2004;28(3):247-53.

63. Kubo T, Shimose S, Fujimori J, Furuta T, Arihiro K, Ochi M. Does expression of glucose transporter protein-1 relate to prognosis and angiogenesis in osteosarcoma? Clin Orthop Relat Res. 2015:473(1):305-10.

64. Mukha A, Dubrovska A. Metabolic targeting of cancer stem cells. Front Oncol. 2020;10:537930.

65. Teoh ST, Lunt SY. Metabolism in cancer metastasis: bioenergetics, biosynthesis, and beyond. Wiley Interdiscip Rev Syst Biol Med. 2018. https://doi.org/10.1002/wsbm.1406.

66. Zhong Z, Mao S, Lin H, Li H, Lin J, Lin JM. Alteration of intracellular metabolome in osteosarcoma stem cells revealed by liquid chromatography-tandem mass spectrometry. Talanta. 2019;204:6-12.

67. Mizushima E, Tsukahara T, Emori M, Murata K, Akamatsu A, Shibayama $Y$, et al. Osteosarcoma-initiating cells show high aerobic glycolysis and attenuation of oxidative phosphorylation mediated by LIN28B. Cancer Sci. 2020;111(1):36-46.

68. Losman JA, Kaelin WG Jr. What a difference a hydroxyl makes: mutant IDH, (R)-2-hydroxyglutarate, and cancer. Genes Dev. 2013;27(8):836-52.

69. Liu X, Kato Y, Kaneko MK, Sugawara M, Ogasawara S, Tsujimoto Y, et al. Isocitrate dehydrogenase 2 mutation is a frequent event in osteosarcoma detected by a multi-specific monoclonal antibody MsMab-1. Cancer Med. 2013;2(6):803-14.

70. Ghanavat M, Shahrouzian M, Deris Zayeri Z, Banihashemi S, Kazemi SM, Saki N. Digging deeper through glucose metabolism and its regulators in cancer and metastasis. Life Sci. 2021;264:118603.
71. Kim JW, Gao P, Liu YC, Semenza GL, Dang CV. Hypoxia-inducible factor 1 and dysregulated c-Myc cooperatively induce vascular endothelial growth factor and metabolic switches hexokinase 2 and pyruvate dehydrogenase kinase 1. Mol Cell Biol. 2007;27(21):7381-93.

72. Wang DW, Wu L, Cao Y, Yang L, Liu W, et al. A novel mechanism of mTORC1-mediated serine/glycine metabolism in osteosarcoma development. Cell Signal. 2017;29:107-14.

73. Nogueira LM, Lavigne JA, Chandramouli GV, Lui H, Barrett JC, Hursting SD. Dose-dependent effects of calorie restriction on gene expression, metabolism, and tumor progression are partially mediated by insulinlike growth factor-1. Cancer Med. 2012;1(2):275-88.

74. Klement RJ, Fink MK. Dietary and pharmacological modification of the insulin/IGF-1 system: exploiting the full repertoire against cancer. Oncogenesis. 2016;5:e193.

75. Li YS, Liu Q, He HB, Luo W. The possible role of insulin-like growth factor-1 in osteosarcoma. Curr Probl Cancer. 2019;43(3):228-35.

76. Weiss JM. The promise and peril of targeting cell metabolism for cancer therapy. Cancer Immunol Immunother. 2020;69(2):255-61.

77. Wegiel B, Vuerich M, Daneshmandi S, Seth P. Metabolic switch in the tumor microenvironment determines immune responses to anticancer therapy. Front Oncol. 2018;8:284.

78. Chang CH, Qiu J, O'Sullivan D, Buck MD, Noguchi T, Curtis JD, et al. Metabolic competition in the tumor microenvironment is a driver of cancer progression. Cell. 2015;162(6):1229-41.

79. Dey P, Kimmelman AC, DePinho RA. Metabolic codependencies in the tumor microenvironment. Cancer Discov. 2021;11(5):1067-81.

80. Husain Z, Huang Y, Seth P, Sukhatme VP. Tumor-derived lactate modifies antitumor immune response: effect on myeloid-derived suppressor cells and NK cells. J Immunol. 2013;191(3):1486-95.

81. Luengo A, Gui DY, Vander Heiden MG. Targeting metabolism for cancer therapy. Cell Chem Biol. 2017:24(9):1161-80.

82. Kim SY. Targeting cancer energy metabolism: a potential systemic cure for cancer. Arch Pharm Res. 2019;42(2):140-9.

83. Defrancesco I, Zibellini S, Boveri E, Frigeni M, Ferretti W, Rizzo E, et al. Targeted Next Generation Sequencing Reveals Molecular Heterogeneity in non-CLL Clonal B-Cell Lymphocytosis. Hematol Oncol. 2020;38(5):689-97.

84. Zhao B, Luo J, Wang Y, Zhou L, Che J, Wang F, et al. Metformin suppresses self-renewal ability and tumorigenicity of osteosarcoma stem cells via reactive oxygen species-mediated apoptosis and autophagy. Oxid Med Cell Longev. 2019;2019:9290728.

85. Ren L, Ruiz-Rodado V, Dowdy T, Huang S, Issaq SH, Beck J, et al. Glutaminase-1 (GLS1) inhibition limits metastatic progression in osteosarcoma. Cancer Metab. 2020;8:4

86. Gao F, Zuo Q, Jiang T, Song H, Zhou J. A newly synthesized oleanolic acid derivative inhibits the growth of osteosarcoma cells in vitro and in vivo by decreasing c-MYC-dependent glycolysis. J Cell Biochem. 2019;120(6):9264-76.

87. O'Flanagan $\mathrm{CH}$, Smith LA, McDonell SB, Hursting SD. When less may be more: calorie restriction and response to cancer therapy. BMC Med. 2017:15(1):106.

88. Most J, Tosti V, Redman LM, Fontana L. Calorie restriction in humans: an update. Ageing Res Rev. 2017;39:36-45.

89. Zhou Y, Li S, Li J, Wang D, Li Q. Effect of microRNA-135a on cell proliferation, migration, invasion, apoptosis and tumor angiogenesis through the IGF-1/PI3K/Akt signaling pathway in non-small cell lung cancer. Cell Physiol Biochem. 2017;42(4):1431-46.

90. LuY, Tao F, Zhou MT, Tang KF. The signaling pathways that mediate the anti-cancer effects of caloric restriction. Pharmacol Res. 2019:141:512-20.

91. Harvey AE, Lashinger LM, Otto G, Nunez NP, Hursting SD. Decreased systemic IGF-1 in response to calorie restriction modulates murine tumor cell growth, nuclear factor-kappaB activation, and inflammationrelated gene expression. Mol Carcinog. 2013;52(12):997-1006.

92. Blando J, Moore T, Hursting S, Jiang G, Saha A, Beltran L, et al. Dietary energy balance modulates prostate cancer progression in Hi-Myc mice. Cancer Prev Res. 2011;4(12):2002-14.

93. Ma Z, Parris AB, Howard EW, Shi Y, Yang S, Jiang Y, et al. Caloric restriction inhibits mammary tumorigenesis in MMTV-ErbB2 transgenic mice through the suppression of ER and ErbB2 pathways and inhibition of 
epithelial cell stemness in premalignant mammary tissues. Carcinogenesis. 2018;39(10):1264-73.

94. Lanza-Jacoby S, Yan G, Radice G, LePhong C, Baliff J, Hess R. Calorie restriction delays the progression of lesions to pancreatic cancer in the LSL-KrasG12D; Pdx-1/Cre mouse model of pancreatic cancer. Exp Biol Med (Maywood). 2013;238(7):787-97.

95. Devlin KL, Sanford T, Harrison LM, LeBourgeois P, Lashinger LM, Mambo $E$, et al. Stage-specific microRNAs and their role in the anticancer effects of calorie restriction in a rat model of ER-positive luminal breast cancer. PLOS ONE. 2016;11(7):e0159686.

96. Galet C, Gray A, Said JW, Castor B, Wan J, Beltran PJ, et al. Effects of calorie restriction and IGF-1 receptor blockade on the progression of 22Rv1 prostate cancer xenografts. Int J Mol Sci. 2013;14(7):13782-95.

97. Simone BA, Palagani A, Strickland K, Ko K, Jin L, Lim MK, et al. Caloric restriction counteracts chemotherapy-induced inflammation and increases response to therapy in a triple negative breast cancer model. Cell Cycle. 2018;17(13):1536-44.

98. Saleh AD, Simone BA, Palazzo J, Savage JE, Sano Y, Dan T, et al. Caloric restriction augments radiation efficacy in breast cancer. Cell Cycle. 2013;12(12):1955-63.

99. Manukian G, Kivolowitz C, DeAngelis T, Shastri AA, Savage JE, Camphausen $\mathrm{K}$, et al. Caloric restriction impairs regulatory t cells within the tumor microenvironment after radiation and primes effector $T$ cells. Int J Radiat Oncol Biol Phys. 2021;110(5):1341-9.

100. Wei M, Brandhorst S, Shelehchi M, Mirzaei H, Cheng CW, Budniak J, et al. Fasting-mimicking diet and markers/risk factors for aging, diabetes, cancer, and cardiovascular disease. Sci Transl Med. 2017;9(377):eaai8700.

101. Nencioni A, Caffa I, Cortellino S, Longo VD. Fasting and cancer: molecular mechanisms and clinical application. Nat Rev Cancer. 2018;18(11):707-19.

102. Zhao X, Yang J, Huang R, Guo M, Zhou Y, Xu L. The role and its mechanism of intermittent fasting in tumors: friend or foe? Cancer Biol Med. 2021;18(1):63-73.

103. Bianchi G, Martella R, Ravera S, Marini C, Capitanio S, Orengo A, et al. Fasting induces anti-Warburg effect that increases respiration but reduces ATP-synthesis to promote apoptosis in colon cancer models. Oncotarget. 2015;6(14):11806-19.

104. Kang JS. Dietary restriction of amino acids for cancer therapy. Nutr Metab. 2020;17:20.

105. Yin J, Ren W, Huang X, Li T, Yin Y. Protein restriction and cancer. Biochim Biophys Acta Rev Cancer. 2018;1869(2):256-62.

106. Marsh J, Mukherjee P, Seyfried TN. Akt-dependent proapoptotic effects of dietary restriction on late-stage management of a phosphatase and tensin homologue/tuberous sclerosis complex 2-deficient mouse astrocytoma. Clin Cancer Res. 2008;14(23):7751-62.

107. Sun P, Wang H, He Z, Chen X, Wu Q, Chen W, et al. Fasting inhibits colorectal cancer growth by reducing M2 polarization of tumor-associated macrophages. Oncotarget. 2017:8(43):74649-60.

108. Thomas JA 2nd, Antonelli JA, Lloyd JC, Masko EM, Poulton SH, Phillips $T E$, et al. Effect of intermittent fasting on prostate cancer tumor growth in a mouse model. Prostate Cancer Prostatic Dis. 2010;13(4):350-5.

109. Weng ML, Chen WK, Chen XY, Lu H, Sun ZR, Yu Q, et al. Fasting inhibits aerobic glycolysis and proliferation in colorectal cancer via the Fdft1mediated AKT/mTOR/HIF1alpha pathway suppression. Nat Commun. 2020;11(1):1869.

110. Ajona D, Ortiz-Espinosa S, Lozano T, Exposito F, Calvo A, Valencia K, et al. Short-term starvation reduces IGF-1 levels to sensitize lung tumors to PD-1 immune checkpoint blockade. Nat Cancer. 2020;1 (1):75-85.

111. Raffaghello L, Lee C, Safdie FM, Wei M, Madia F, Bianchi G, et al. Starvation-dependent differential stress resistance protects normal but not cancer cells against high-dose chemotherapy. Proc Natl Acad Sci USA. 2008;105(24):8215-20.

112. Lee C, Raffaghello L, Brandhorst S, Safdie FM, Bianchi G, MartinMontalvo A, et al. Fasting cycles retard growth of tumors and sensitize a range of cancer cell types to chemotherapy. Sci Transl Med. 2012;4(124):12427.

113. de la Cruz BM, Stemler KM, Jeter-Jones S, Fujimoto TN, Molkentine J, Asencio Torres GM, et al. Fasting reduces intestinal radiotoxicity, enabling dose-escalated radiation therapy for pancreatic cancer. Int J Radiat Oncol Biol Phys. 2019;105(3):537-47.
114. Tsuda M, Ishiguro H, Toriguchi N, Masuda N, Bando H, Ohgami M, et al. Overnight fasting before lapatinib administration to breast cancer patients leads to reduced toxicity compared with nighttime dosing: a retrospective cohort study from a randomized clinical trial. Cancer Med. 2020;9(24):9246-55.

115. Zorn S, Ehret J, Schauble R, Rautenberg B, Ihorst G, Bertz H, et al. Impact of modified short-term fasting and its combination with a fasting supportive diet during chemotherapy on the incidence and severity of chemotherapy-induced toxicities in cancer patients-a controlled cross-over pilot study. BMC Cancer. 2020;20(1):578.

116. Safdie F, Brandhorst S, Wei M, Wang W, Lee C, Hwang S, et al. Fasting enhances the response of glioma to chemo- and radiotherapy. PLoS ONE. 2012;7(9):e44603.

117. Allen BG, Bhatia SK, Anderson CM, Eichenberger-Gilmore JM, Sibenaller ZA, Mapuskar KA, et al. Ketogenic diets as an adjuvant cancer therapy: history and potential mechanism. Redox Biol. 2014;2:963-70.

118. Oliveira CLP, Mattingly S, Schirrmacher R, Sawyer MB, Fine EJ, Prado CM. A nutritional perspective of ketogenic diet in cancer: a narrative review. J Acad Nutr Diet. 2018;1 18(4):668-88.

119. Weber DD, Aminzadeh-Gohari S, Tulipan J, Catalano L, Feichtinger RG, Kofler B. Ketogenic diet in the treatment of cancer-Where do we stand? Mol Metab. 2020;33:102-21.

120. Klement RJ, Schafer G, Sweeney RA. A ketogenic diet exerts beneficial effects on body composition of cancer patients during radiotherapy: an interim analysis of the KETOCOMP study. J Tradit Complement Med. 2020;10(3):180-7.

121. Klement RJ. Beneficial effects of ketogenic diets for cancer patients: a realist review with focus on evidence and confirmation. Med Oncol. 2017;34(8):132.

122. Zhang N, Liu C, Jin L, Zhang R, Wang T, Wang Q, et al. Ketogenic diet elicits antitumor properties through inducing oxidative stress, inhibiting MMP-9 expression, and rebalancing M1/M2 tumor-associated macrophage phenotype in a mouse model of colon cancer. J Agric Food Chem. 2020;68(40):11182-96.

123. Licha D, Vidali S, Aminzadeh-Gohari S, Alka O, Breitkreuz L, Kohlbacher $\mathrm{O}$, et al. Untargeted metabolomics reveals molecular effects of ketogenic diet on healthy and tumor xenograft mouse models. Int J Mol Sci. 2019;20(16):3873.

124. Urbain P, Strom L, Morawski L, Wehrle A, Deibert P, Bertz H. Impact of a 6-week non-energy-restricted ketogenic diet on physical fitness, body composition and biochemical parameters in healthy adults. Nutr Metab (Lond). 2017:14:17.

125. Lussier DM, Woolf EC, Johnson JL, Brooks KS, Blattman JN, Scheck AC. Enhanced immunity in a mouse model of malignant glioma is mediated by a therapeutic ketogenic diet. BMC Cancer. 2016;16:310.

126. Seyfried TN, Sanderson TM, El-Abbadi MM, McGowan R, Mukherjee P. Role of glucose and ketone bodies in the metabolic control of experimental brain cancer. Br J Cancer. 2003;89(7):1375-82.

127. Zhou W, Mukherjee P, Kiebish MA, Markis WT, Mantis JG, Seyfried TN The calorically restricted ketogenic diet, an effective alternative therapy for malignant brain cancer. Nutr Metab. 2007:4:5.

128. Martuscello RT, Vedam-Mai V, McCarthy DJ, Schmoll ME, Jundi MA, Louviere $C D$, et al. A supplemented high-fat low-carbohydrate diet for the treatment of glioblastoma. Clin Cancer Res. 2016;22(10):2482-95.

129. Stafford P, Abdelwahab MG, Kim DY, Preul MC, Rho JM, Scheck AC. The ketogenic diet reverses gene expression patterns and reduces reactive oxygen species levels when used as an adjuvant therapy for glioma. Nutr Metab. 2010;7:74.

130. Woolf EC, Curley KL, Liu Q, Turner GH, Charlton JA, Preul MC, et al. The ketogenic diet alters the hypoxic response and affects expression of proteins associated with angiogenesis, invasive potential and vascular permeability in a mouse glioma model. PLoS ONE. 2015;10(6):e0130357.

131. Morscher RJ, Aminzadeh-Gohari S, Feichtinger RG, Mayr JA, Lang $R$, Neureiter $D$, et al. Inhibition of neuroblastoma tumor growth by ketogenic diet and/or calorie restriction in a CD1-Nu mouse model. PLOS ONE. 2015;10(6):e0129802.

132. Dang MT, Wehrli S, Dang CV, Curran T. The ketogenic diet does not affect growth of hedgehog pathway medulloblastoma in mice. PLoS ONE. 2015;10(7):e0133633. 
133. Hsieh MH, Choe JH, Gadhvi J, Kim YJ, Arguez MA, Palmer M, et al. p63 and SOX2 dctate glucose reliance and metabolic vulnerabilities in squamous cell carcinomas. Cell Rep. 2019;28(7):1860-78.

134. Gluschnaider U, Hertz R, Ohayon S, Smeir E, Smets M, Pikarsky E, et al. Long-chain fatty acid analogues suppress breast tumorigenesis and progression. Cancer Res. 2014;74(23):6991-7002.

135. Kim HS, Masko EM, Poulton SL, Kennedy KM, Pizzo SV, Dewhirst MW, et al. Carbohydrate restriction and lactate transporter inhibition in a mouse xenograft model of human prostate cancer. BJU Int. 2012;110(7):1062-9.

136. Nakamura K, Tonouchi H, Sasayama A, Ashida K. A ketogenic formula prevents tumor progression and cancer cachexia by attenuating systemic inflammation in colon 26 tumor-bearing mice. Nutrients. 2018;10(2):206.

137. Hao GW, Chen YS, He DM, Wang HY, Wu GH, Zhang B. Growth of human colon cancer cells in nude mice is delayed by ketogenic diet with or without omega-3 fatty acids and medium-chain triglycerides. Asian Pac J Cancer Prev. 2015;16(5):2061-8.

138. Otto C, Kaemmerer U, Illert B, Muehling B, Pfetzer N, Wittig R, et al. Growth of human gastric cancer cells in nude mice is delayed by a ketogenic diet supplemented with omega-3 fatty acids and medium-chain triglycerides. BMC Cancer. 2008;8:122.

139. Healy ME, Chow JD, Byrne FL, Breen DS, Leitinger N, Li C, et al. Dietary effects on liver tumor burden in mice treated with the hepatocellular carcinogen diethylnitrosamine. J Hepatol. 2015;62(3):599-606.

140. Byrne FL, Hargett SR, Lahiri S, Roy RJ, Berr SS, Caldwell SH, et al. Serial MRI imaging reveals minimal impact of ketogenic diet on established liver tumor growth. Cancers. 2018;10(9):312.

141. Xia $S$, Lin $R$, Jin $L$, Zhao L, Kang HB, Pan $Y$, et al. Prevention of dietaryfat-fueled ketogenesis attenuates BRAF V600E tumor growth. Cell Metab. 2017:25(2):358-73.

142. Abdelwahab MG, Fenton KE, Preul MC, Rho JM, Lynch A, Stafford P, et al. The ketogenic diet is an effective adjuvant to radiation therapy for the treatment of malignant glioma. PLoS ONE. 2012;7(5):e36197.

143. Maeyama M, Tanaka K, Nishihara M, Irino Y, Shinohara M, Nagashima $\mathrm{H}$, et al. Metabolic changes and anti-tumor effects of a ketogenic diet combined with anti-angiogenic therapy in a glioblastoma mouse model. Sci Rep. 2021;11(1):79.

144. Mukherjee P, Augur ZM, Li M, Hill C, Greenwood B, Domin MA, et al. Therapeutic benefit of combining calorie-restricted ketogenic diet and glutamine targeting in late-stage experimental glioblastoma. Commun Biol. 2019:2:200

145. Aminzadeh-Gohari S, Feichtinger RG, Vidali S, Locker F, Rutherford T, O'Donnel M, et al. A ketogenic diet supplemented with mediumchain triglycerides enhances the anti-tumor and anti-angiogenic efficacy of chemotherapy on neuroblastoma xenografts in a CD1-nu mouse model. Oncotarget. 2017:8(39):64728-44.

146. Zou Y, Fineberg S, Pearlman A, Feinman RD, Fine EJ. The effect of a ketogenic diet and synergy with rapamycin in a mouse model of breast cancer. PLoS ONE. 2020;15(12):e0233662

147. Allen BG, Bhatia SK, Buatti JM, Brandt KE, Lindholm KE, Button AM, et al. Ketogenic diets enhance oxidative stress and radio-chemotherapy responses in lung cancer xenografts. Clin Cancer Res. 2013;19(14):3905-13.

148. Fine EJ, Segal-Isaacson CJ, Feinman RD, Herszkopf S, Romano MC, Tomuta N, et al. Targeting insulin inhibition as a metabolic therapy in advanced cancer: a pilot safety and feasibility dietary trial in 10 patients. Nutrition. 2012:28(10):1028-35.

149. Tan-Shalaby JL, Carrick J, Edinger K, Genovese D, Liman AD, Passero $V A$, et al. Modified Atkins diet in advanced malignancies-final results of a safety and feasibility trial within the Veterans Affairs Pittsburgh Healthcare System. Nutr Metab. 2016;13:52.

150. Ok JH, Lee H, Chung HY, Lee SH, Choi EJ, Kang CM, et al. The potential use of a ketogenic diet in pancreatobiliary cancer patients after pancreatectomy. Anticancer Res. 2018;38(11):6519-27.

151. Iyikesici MS. Feasibility study of metabolically supported chemotherapy with weekly carboplatin/paclitaxel combined with ketogenic diet, hyperthermia and hyperbaric oxygen therapy in metastatic non-small cell lung cancer. Int J Hyperthermia. 2019;36(1):446-55.
152. Woodhouse C, Ward T, Gaskill-Shipley M, Chaudhary R. Feasibility of a modified atkins diet in glioma patients during radiation and its effect on radiation sensitization. Curr Oncol. 2019:26(4):e433-8.

153. Martin-McGill KJ, Marson AG, Tudur Smith C, Jenkinson MD. The modified ketogenic diet in adults with glioblastoma: an evaluation of feasibility and deliverability within the National Health Service. Nutr Cancer. 2018;70(4):643-9.

154. Rieger J, Bahr O, Maurer GD, Hattingen E, Franz K, Brucker D, et al. ERGO: a pilot study of ketogenic diet in recurrent glioblastoma. Int J Oncol. 2014;44(6):1843-52

155. Klement RJ, Champ CE, Kammerer U, Koebrunner PS, Krage K, Schafer $\mathrm{G}$, et al. Impact of a ketogenic diet intervention during radiotherapy on body composition: III-final results of the KETOCOMP study for breast cancer patients. Breast Cancer Res. 2020;22(1):94.

156. Cohen CW, Fontaine KR, Arend RC, Alvarez RD, Leath CA III, Huh WK, et al. A ketogenic diet reduces central obesity and serum insulin in women with ovarian or endometrial cancer. J Nutr. 2018;148(8):1253-60.

157. Schroeder U, Himpe B, Pries R, Vonthein R, Nitsch S, Wollenberg B. Decline of lactate in tumor tissue after ketogenic diet: in vivo microdialysis study in patients with head and neck cancer. Nutr Cancer. 2013;65(6):843-9.

158. Rautiainen S, Manson JE, Lichtenstein AH, Sesso HD. Dietary supplements and disease prevention - a global overview. Nat Rev Endocrinol. 2016;12(7):407-20.

159. Hardy ML, Duvall K. Multivitamin/multimineral supplements for cancer prevention: implications for primary care practice. Postgrad Med. 2015;127(1):107-16

160. Paller CJ, Denmeade SR, Carducci MA. Challenges of conducting clinical trials of natural products to combat cancer. Clin Adv Hematol Oncol. 2016:14(6):447-55.

161. Ross JA, Kasum CM. Dietary flavonoids: bioavailability, metabolic effects, and safety. Annu Rev Nutr. 2002;22:19-34.

162. Tang SM, Deng XT, Zhou J, Li QP, Ge XX, Miao L. Pharmacological basis and new insights of quercetin action in respect to its anti-cancer effects. Biomed Pharmacother. 2020;121:109604.

163. Almatroodi SA, Alsahli MA, Almatroudi A, Verma AK, Aloliqi A, Allemailem KS, et al. Potential therapeutic targets of quercetin, a plant flavonol, and its role in the therapy of various types of cancer through the modulation of various cell signaling pathways. Molecules. 2021;26(5):1315

164. Hashemzaei M, Delarami Far A, Yari A, Heravi RE, Tabrizian K, Taghdisi $\mathrm{SM}$, et al. Anticancer and apoptosis inducing effects of quercetin in vitro and in vivo. Oncol Rep. 2017;38(2):819-28.

165. Liang W, Li X, Li C, Liao L, Gao B, Gan H, et al. Quercetin-mediated apoptosis via activation of the mitochondrial-dependent pathway in MG-63 osteosarcoma cells. Mol Med Rep. 2011;4(5):1017-23.

166. Li S, Pei Y, Wang W, Liu F, Zheng K, Zhang X. Quercetin suppresses the proliferation and metastasis of metastatic osteosarcoma cells by inhibiting parathyroid hormone receptor 1. Biomed Pharmacother. 2019:114:108839.

167. Suh DK, Lee EJ, Kim HC, Kim JH. Induction of G(1)/S phase arrest and apoptosis by quercetin in human osteosarcoma cells. Arch Pharm Res. 2010;33(5):781-5

168. Berndt K, Campanile C, Muff R, Strehler E, Born W, Fuchs B. Evaluation of quercetin as a potential drug in osteosarcoma treatment. Anticancer Res. 2013:33(4):1297-306.

169. Wu B, Zeng W, Ouyang W, Xu Q, Chen J, Wang B, et al. Quercetin induced NUPR1-dependent autophagic cell death by disturbing reactive oxygen species homeostasis in osteosarcoma cells. J Clin Biochem Nutr. 2020;67(2):137-45.

170. Lan H, Hong W, Fan P, Qian D, Zhu J, Bai B. Quercetin inhibits cell migration and invasion in human osteosarcoma cells. Cell Physiol Biochem. 2017:43(2):553-67.

171. Andres S, Pevny S, Ziegenhagen R, Bakhiya N, Schafer B, Hirsch-Ernst $\mathrm{Kl}$, et al. Safety aspects of the use of quercetin as a dietary supplement. Mol Nutr Food Res. 2018. https://doi.org/10.1002/mnfr.201700447.

172. Harwood M, Danielewska-Nikiel B, Borzelleca JF, Flamm GW, Williams GM, Lines TC. A critical review of the data related to the safety of quercetin and lack of evidence of in vivo toxicity, including 
lack of genotoxic/carcinogenic properties. Food Chem Toxicol. 2007;45(11):2179-205.

173. Bauersfeld SP, Kessler CS, Wischnewsky M, Jaensch A, Steckhan N, Stange $R$, et al. The effects of short-term fasting on quality of life and tolerance to chemotherapy in patients with breast and ovarian cancer: a randomized cross-over pilot study. BMC Cancer. 2018;18(1):476.

174. Turbitt WJ, Demark-Wahnefried W, Peterson CM, Norian LA. Targeting glucose metabolism to enhance immunotherapy: emerging evidence on intermittent fasting and calorie restriction mimetics. Front Immunol. 2019;10:1402
175. Orgel E, Framson C, Buxton R, Kim J, Li G, Tucci J, et al. Caloric and nutrient restriction to augment chemotherapy efficacy for acute lymphoblastic leukemia: the IDEAL trial. Blood Adv. 2021:5(7):1853-61.

\section{Publisher's Note}

Springer Nature remains neutral with regard to jurisdictional claims in published maps and institutional affiliations.
Ready to submit your research? Choose BMC and benefit from:

- fast, convenient online submission

- thorough peer review by experienced researchers in your field

- rapid publication on acceptance

- support for research data, including large and complex data types

- gold Open Access which fosters wider collaboration and increased citations

- maximum visibility for your research: over $100 \mathrm{M}$ website views per year

At BMC, research is always in progress.

Learn more biomedcentral.com/submissions 